\title{
Erratum to: Metabolism of glucose and xylose as single and mixed feed in Debaryomyces nepalensis NCYC 3413: production of industrially important metabolites
}

Sawan Kumar • Sathyanarayana N. Gummadi

Published online: 8 February 2011

(C) Springer-Verlag 2011

Erratum to: Appl Microbiol Biotechnol

DOI 10.1007/s00253-010-2997-1

The original version of this article, unfortunately, contained a mistake.

The statement "With an initial glucose concentration of $200 \mathrm{~g} / \mathrm{l}, D$. nepalensis produced ethanol at a concentration $(35.8 \mathrm{~g} / \mathrm{l})$ higher than reported for Kluyveromyces sp. $(8.2 \mathrm{~g} / \mathrm{l})$ and comparable with $39.4 \mathrm{~g} / \mathrm{l}$ reported for Zygosaccharomyces bailii (Kumar et al. 2009; Merico et al. 2003) should be presented as "With an initial glucose concentration of $200 \mathrm{~g} / \mathrm{l}$, D. nepalensis produced ethanol at a concentration $(35.8 \mathrm{~g} / \mathrm{l})$ lower than reported for Kluyveromyces sp. $(82 \mathrm{~g} / \mathrm{l})$ and comparable with $39.4 \mathrm{~g} / \mathrm{l}$ reported for Zygosaccharomyces bailii (Kumar et al. 2009; Merico et al. 2003)."

The online version of the original article can be found at http://dx.doi. org/10.1007/s00253-010-2997-1.

S. Kumar· S. N. Gummadi $(\bowtie)$

Applied and Industrial Microbiology Laboratory, Department of

Biotechnology, Indian Institute of Technology-Madras,

Chennai, India

e-mail: gummadi@iitm.ac.in 